\title{
Mechanical stability of retained austenite in aluminum-containing medium-Mn steel deformed at different temperatures
}

\author{
Aleksandra Kozłowska ${ }^{1}\left[\mathrm{Krzysztof} \mathrm{Radwański}^{2} \cdot \mathrm{Krzysztof} \mathrm{Matus}^{1} \cdot\right.$ Ludovic Samek $^{3} \cdot$ Adam Grajcar $^{1}$
}

Received: 21 April 2020 / Revised: 30 November 2020 / Accepted: 4 January 2021 / Published online: 25 January 2021

(C) The Author(s) 2021

\begin{abstract}
The thermal and mechanical stabilities of retained austenite in aluminum-containing medium-Mn $0.16 \mathrm{C}-4.7 \mathrm{Mn}-1.6 \mathrm{Al}-$ $0.2 \mathrm{Si}$ sheet steel were investigated. The strain-induced martensitic transformation in Mn TRIP steel was studied at different temperatures. Static tensile tests were carried out at the temperature ranging from -60 to $200{ }^{\circ} \mathrm{C}$. The tests allowed to study the influence of the temperature on austenite-to-martensite transformation kinetics. The interrupted tensile tests and corresponding X-ray measurements of retained austenite amount were performed to determine the mechanical stability of retained austenite using the Sugimoto model. The microstructure changes were investigated using scanning electron microscopy (SEM), electron backscatter diffraction (EBSD), X-ray diffraction (XRD) and transmission electron microscopy (TEM) techniques. Observed results reflected the effects of deformation temperature on the mechanical stability of retained austenite and the corresponding response of this phase to martensitic transformation. It was found that an increase in the deformation temperature resulted in the reduced intensity of the TRIP effect due to the higher mechanical stability of retained austenite. At the highest deformation temperature $\left(200^{\circ} \mathrm{C}\right)$, the evidence of thermally activated processes affecting the mechanical behavior was identified.
\end{abstract}

Keywords Medium-Mn steel $\cdot$ Mechanical behavior $\cdot$ Stability of retained austenite $\cdot$ Multiphase microstructure $\cdot$ Elevated temperature · TRIP effect

\section{Introduction}

Advanced high-strength steels (AHSS) are ideally suited for automotive applications. They should meet demands for important lightweight reduction in vehicles and increased passenger safety at the lowest production costs. Modern constructional sheet steels dedicated to the automotive industry should meet demands for obtaining car's lightweight and safety at the lowest production costs [1]. Medium-Mn transformation-induced plasticity (TRIP) steels containing

Aleksandra Kozłowska

aleksandra.kozlowska@polsl.pl

1 Department of Engineering Materials and Biomaterials, Silesian University of Technology, 18a Konarskiego Street, 44-100 Gliwice, Poland

2 Łukasiewicz Research Network-Institute for Ferrous Metallurgy, 12-14 K. Miarki Street, 44-100 Gliwice, Poland

3 Faculty for Engineering and Environmental Sciences, University of Applied Sciences Upper Austria, 23 Stelzhamerstrasse, 4600 Wels, Austria
3-8 wt \% Mn are considered as a promising candidate for lightweight automotive applications due to their excellent mechanical properties, good formability and relatively low alloying cost (the reduced manganese content) [2]. The stability of retained austenite (RA) is an essential factor affecting the mechanical properties of steels exhibiting the austenite-to-martensite transformation [3]. The retained austenite characterized by very high stability is not able to transform into strain-induced martensite, and as a result such steel sheets show the low plasticity [4]. Retained austenite with low stability transforms into martensite rapidly at small strains [5]; thus, the steel cannot achieve the satisfactory work hardening rate [6]. Therefore, research efforts are focused on designing the chemical composition and processing parameters which allow producing the optimal microstructure with a volume fraction of retained austenite characterized by the tailored stability [7]. It enables one to obtain favorable combination of mechanical properties [8].

The stability of retained austenite phase is influenced by many factors [9], including the chemical composition (in particular $\mathrm{C}$ and $\mathrm{Mn}$ ), grain size, morphology, stress state, 
strain rate and temperature [10]. Some amount of retained austenite transforms into strain-induced martensite during manufacturing operations [11] such as stamping, bending and drawing [12]. The remaining part of RA is able to undergo the martensitic transformation during crush events [13]. In both cases, there is a temperature factor associated with the friction during forming operations and adiabatic heating, which affect the kinetics of strain-induced martensitic transformation [14].

The effect of deformation temperature in a range $20-200{ }^{\circ} \mathrm{C}$ on the TRIP effect has been investigated by Kim et al. [15] and Rong et al. [16] in multiphase TRIP-aided steels. However, more studies concern the temperaturedependent deformation mechanism [17] and work hardening behavior [18] of high-Mn austenitic steels. It is reported in the literature that the stability of retained austenite gradually increases with increasing the deformation temperature. Rong et al. [16] reported that the maximum efficiency of TRIP effect in Fe-0.11C-1.65Mn-0.62Si steel was obtained at $15^{\circ} \mathrm{C}$. An increase in deformation temperature to $110{ }^{\circ} \mathrm{C}$ resulted in a 50\% decrease in the amount of retained austenite (RA) transformed into martensite. In case of the high-Mn steels, a similar tendency was observed by Asghari et al. [17] and Li et al. [18]. Rana et al. [19] observed in the range from -60 to $100{ }^{\circ} \mathrm{C}$ that the retained austenite stability of the $\mathrm{Fe}-0.14 \mathrm{C}-10 \mathrm{Mn}-1.7 \mathrm{Al}-0.2 \mathrm{Si}$ steel increased, leading to the reduction in tensile strength. Chen et al. [20] noted that for the $\mathrm{Fe}-0.2 \mathrm{C}-5 \mathrm{Mn}$ steel deformed at temperatures higher than $100{ }^{\circ} \mathrm{C}$ the importance of the TRIP effect decreases, whereas thermally activated processes during or after plastic deformation play an important role.

The optimization of retained austenite stability is one of the most important issue in designing advanced highstrength steels (AHSS). The multiphase steels should provide the maximum TRIP effect at specific deformation temperatures. Therefore, the present study was designed to assess the temperature-dependent mechanical stability of retained austenite in a $0.16 \mathrm{C}-4.7 \mathrm{Mn}-1.6 \mathrm{Al}-0.2 \mathrm{Si}$ steel. The results provide the data concerning the effectiveness of the TRIP effect at deformation temperatures in a range -60 to $200{ }^{\circ} \mathrm{C}$, which corresponds to the conditions that occur during metal forming and exploitation conditions of steel products.

\section{Experimental procedure}

\subsection{Material and thermomechanical processing}

The investigated material was a thermomechanically processed $0.16 \mathrm{C}-4.7 \mathrm{Mn}-1.6 \mathrm{Al}-0.2 \mathrm{Si}$ sheet steel. The carbon content below $0.18 \mathrm{wt} \%$ was aimed in order to offer better resistance spot welding for the automotive applications.
The $\mathrm{C}$ content also prevents probability of the Portevin-Le Chatelier (PLC) effect, which is known especially for the 5-10 wt\% Mn TRIP steels [21]. The reduced manganese content makes it a cheaper solution than the high-Mn steels or medium-Mn steels containing 8-12 wt\% Mn [22]. Aluminum and silicon were added to prevent carbide precipitation during the bainitic holding. The calculated critical transformation temperatures of the steel are: $M_{\mathrm{s}}=280^{\circ} \mathrm{C}$, $A_{\mathrm{c} 1}=660{ }^{\circ} \mathrm{C}, A_{\mathrm{c} 3}=898^{\circ} \mathrm{C}$.

The investigated steel was cast in a vacuum induction furnace. Subsequently, the laboratory ingots were homogenized to eliminate the segregation of chemical composition. Afterward, they were hot-forged (in a temperature range of $1200-900^{\circ} \mathrm{C}$ ) and then roughly rolled (four passes). The final thermomechanical processing (Institute for Ferrous Metallurgy, Gliwice) included three passes to a sheet thickness $\sim 4.5 \mathrm{~mm}$ at a finishing deformation temperature of $850{ }^{\circ} \mathrm{C}$. Subsequently, the sheet strip was continuously cooled to the bainitic transformation temperature and isothermally treated at $400{ }^{\circ} \mathrm{C}$ within $300 \mathrm{~s}$ followed by air cooling to room temperature. Time and temperature of isothermal bainitic transformation were chosen based on the results of our previous study conducted by using the Gleeble thermomechanical simulator [23]. At these time-temperature parameters, the optimal amount and stability of retained austenite were obtained. The schematic illustration of the thermomechanical processing applied to the investigated steel is presented in Fig. 1.

\subsection{Tensile tests and microstructural characterization}

The tensile tests were performed using an INSTRON 1195 universal testing machine. For this purpose, flat tensile specimens with $4.5 \mathrm{~mm}$ thickness and $12.5 \mathrm{~mm}$ width machined from the thermomechanically processed sheet along a rolling direction were used. The tests were performed over a temperature range -60 to $200{ }^{\circ} \mathrm{C}$ at a constant strain rate of $10^{-3} \mathrm{~s}^{-1}$ in order to investigate the temperature-dependent mechanical stability of retained austenite. The tensile tests were performed in accordance with the requirements of the ASTM standard [24]. The mechanical properties were determined based on the average values of three measurements per each deformation temperature. The interrupted tensile tests (at 0.025, 0.05 and 0.075 strain levels) and X-ray measurements (three measurements per each sample) of retained austenite amounts at the corresponding strains were performed to determine the mechanical stability of retained austenite using the Sugimoto model [25].

After the tensile tests, a detailed microstructural analysis was performed using qualitative and quantitative assessment techniques. Samples were cut from the necking area. They were prepared using standard metallographic 


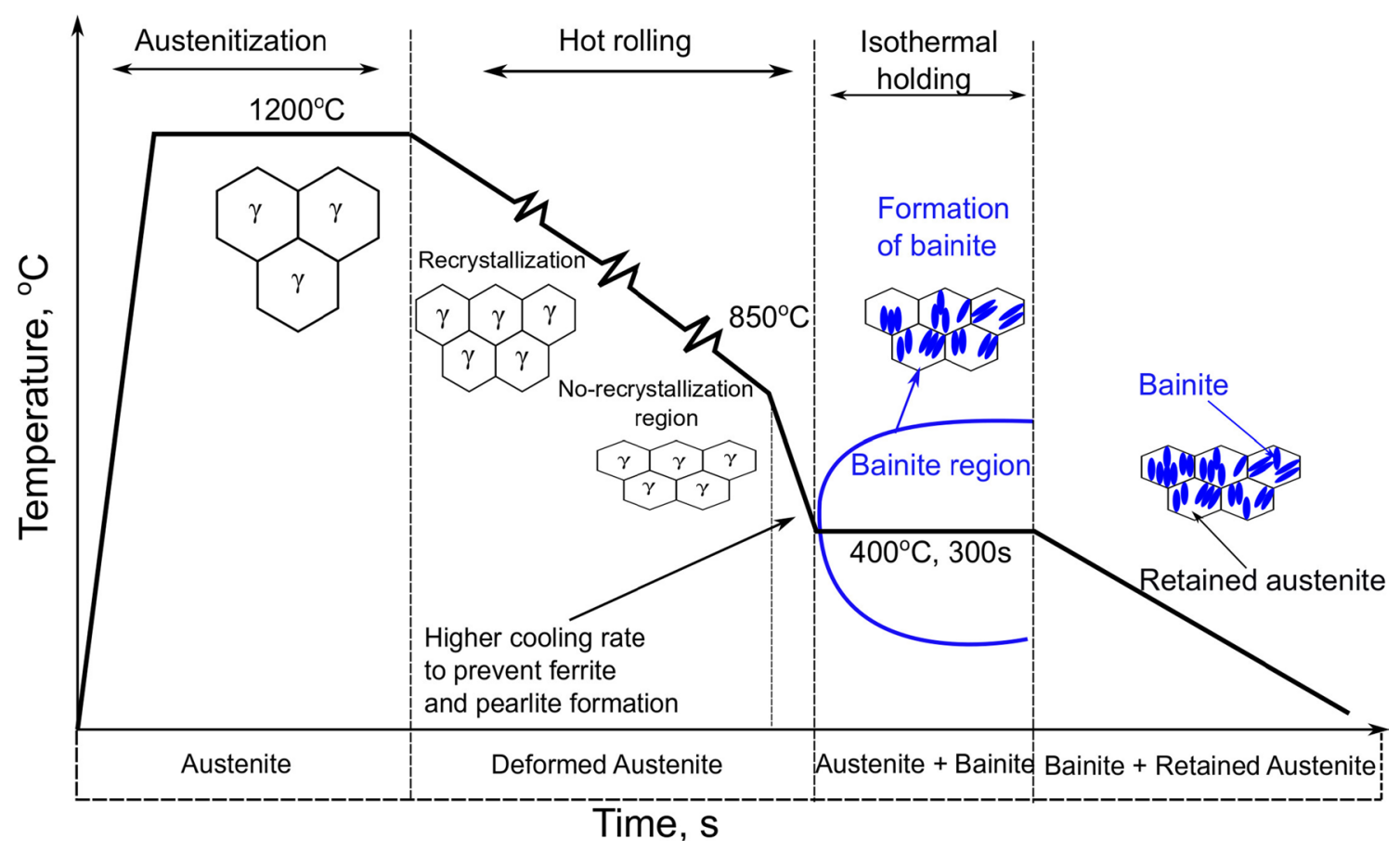

Fig. 1 Schematic illustration of the thermomechanical processing applied to the investigated steel

procedures. Three percentage of nital reagent was used to reveal the microstructure. A scanning electron microscope FEI Inspect-F operating at a voltage of $15 \mathrm{kV}$, working in a secondary electron (SE) detection mode, was employed to characterize the changes in the microstructure at various deformation temperatures. Transmission electron microscopy (TEM) lamellas obtained by focused ion beam (FIB) method (Quanta 3D 200i, FEI) were examined using a Titan 80-300, FEI S/TEM microscope, operating at an accelerating voltage $300 \mathrm{kV}$. To obtain images in a STEM mode, the HAADF and BF/DF detectors were used. The dependence of the intensity of the recorded signal on the square of the atomic number $Z^{2}$ allowed phase and precipitation distinction.

In order to study the strain-induced martensitic transformation kinetics at the various deformation temperatures, EBSD and XRD analyses were performed. The EBSD characterization included phase distribution maps and crystallographic orientation distribution (inverse pole figure) maps. The investigations were performed using the high-resolution JEOL JSM 7200F scanning electron microscope. Kikuchi patterns were collected at an accelerating voltage of $15 \mathrm{kV}$, a working distance of $15 \mathrm{~mm}$ and a step size of $0.025 \mu \mathrm{m}$. The EBSD data were post-analyzed using TSL®OIM (Analysis 8 ) software. The samples were prepared by mechanical grinding and next electrolytic polishing using a TenuPol-5 device working at a voltage of $17 \mathrm{kV}$ for $30 \mathrm{~s}$. The A3 electrolyte by Struers at temperature $0{ }^{\circ} \mathrm{C}$ was used.
X-ray diffraction analysis was carried out by means of an Empyrean PANalytical diffractometer working at a tube voltage of $40 \mathrm{kV}$ and at a tube current of $30 \mathrm{~mA}$. Measurements were performed using the Co-source with an iron filter in configuration with a Pixcel detector. The quantitative determination of the phase fractions at tensile rupture conditions and at interrupted strain levels was realized by using the Averbach-Cohen method according to the ASTM standard [26]. This method is widely used for TRIP-aided multiphase steels [27, 28].

\section{Results and discussion}

\subsection{Microstructure and mechanical stability of retained austenite}

SEM micrograph of steel at the initial state (thermomechanically processed) is shown in Fig. 2. The microstructure of investigated steel is composed of bainitic ferrite laths, retained austenite and some fraction of martensite. Bright, thin layers observed in the microstructure are represented by retained austenite. The presence of martensitic-austenitic (MA) constituents was also observed. Inside the bainitic areas, some fraction of plate carbides can be observed. Their presence is related to the initiation of carbide precipitation during the isothermal holding step following the hot rolling [7]. The XRD pattern of the investigated steel at the 


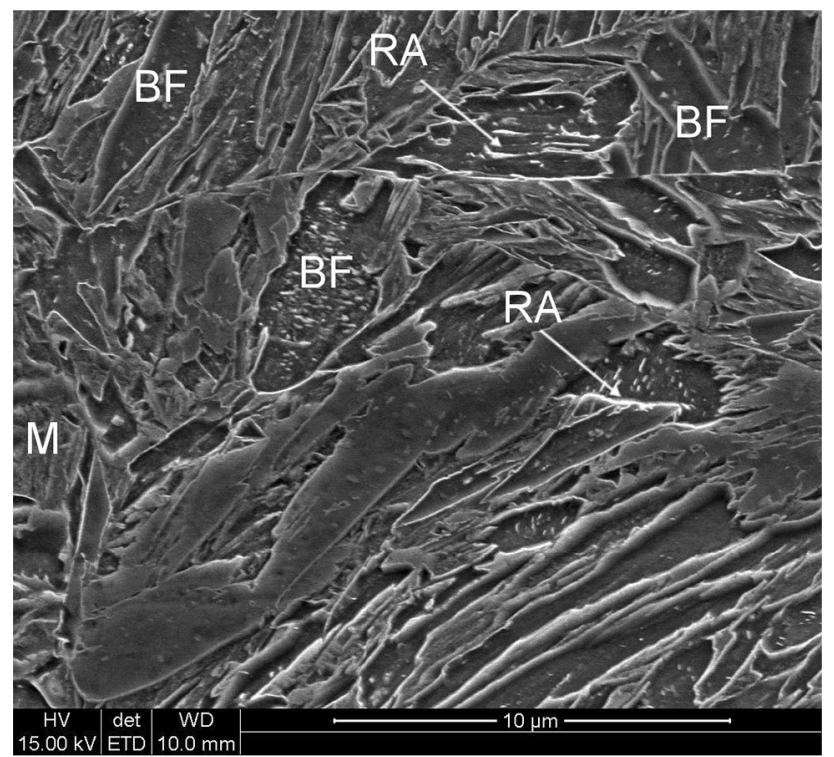

Fig. 2 Scanning electron microscope (SEM) micrograph of investigated steel at the initial state. $M$ martensite, $B F$ bainitic ferrite, $R A$ retained austenite

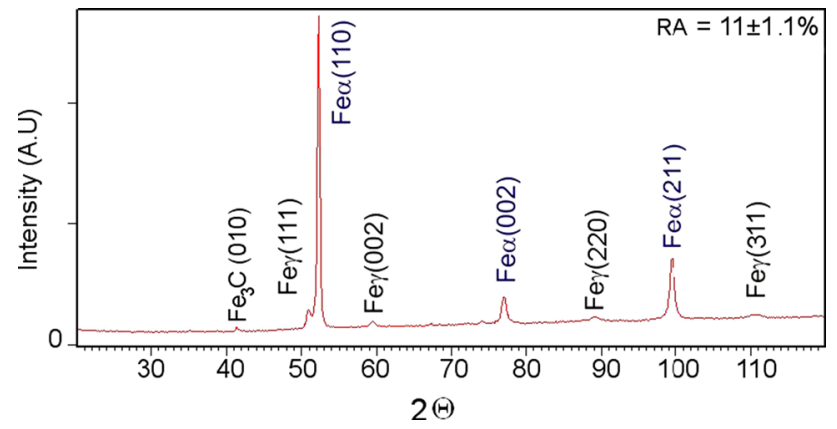

Fig. 3 The X-ray diffraction pattern of investigated steel in the initial state

non-deformed state is illustrated in Fig. 3. The volume fraction of retained austenite estimated based on the integrated intensities of (110) $\alpha,(002) \alpha,(211) \alpha$ peaks and (111) $\gamma$, (002) $\gamma,(220) \gamma,(311) \gamma$ peaks was about $11 \%$.

A detailed analysis of the microstructure evolution during deformation applied at different temperatures allowed for the characterization of the mechanical stability of retained austenite. Figure 4 shows the microstructure of specimens deformed at $20^{\circ} \mathrm{C}, 100{ }^{\circ} \mathrm{C}$ and $200{ }^{\circ} \mathrm{C}$. Independently on the deformation temperature, almost all fractions of RA transformed into strain-induced martensite (Fig. 4a-c). Thus, numerous martensitic areas were formed. Some fraction of retained austenite in the form of thin layers located between bainitic laths can be observed. Despite the addition of 5\% Mn which is known as an austenite stabilizer [29], the $\gamma$ phase was characterized by the low stability [30]. Sugimoto et al. [31] reported that increasing the manganese content reduces the solubility of carbon in austenite. The similar tendency was noted by Sun et al. [32]. They found that increasing the Mn amount from 7 to $10 \%$ resulted in the reduction in the stability of retained austenite due to the lower carbon enrichment of the retained austenite.

Figures 5 and 6 show the EBSD maps of the investigated steel deformed at 20 and $100{ }^{\circ} \mathrm{C}$, respectively. Figures 5a and 6a display color-coded phase maps, in which red color corresponds to the bcc lattice (martensite, bainite) and green color to the fcc lattice (austenite). It can be seen on the phase maps (Figs. 5a and 6a) that almost all fractions of retained austenite transformed into martensite during straining. Inverse pole figures in Figs. $5 \mathrm{~b}$ and $6 \mathrm{~b}$ are characterized by various crystallographic orientations, which are associated with significant deformation during straining.

The XRD patterns and measured austenite fraction of the specimens deformed at the different temperatures are presented in Fig. 7. Almost all fractions of retained austenite transformed into martensite in a temperature range $20-100{ }^{\circ} \mathrm{C}$.

In these cases, XRD measurements show that the amount of retained austenite was lower than $2 \%$. No RA was also observed at the deformation temperatures using the EBSD method (Figs. 5a and 6a). A small amount of RA maintained stable in specimens deformed at the highest temperatures: $140{ }^{\circ} \mathrm{C}$ and $200{ }^{\circ} \mathrm{C}(2.5 \%$ and $3.5 \%$, respectively). The obtained results confirm that the increase in deformation temperature causes an increase in the stability of the retained austenite [30]. It is related to the increase in the stacking fault energy (SFE) value of the austenite [33]. The similar result was observed by Zhang et al. [34] in $\mathrm{Fe}-0.12 \mathrm{C}-10 \mathrm{Mn}-2 \mathrm{Al}-0.05 \mathrm{Si}$ steel deformed in a temperature range -50 to $100{ }^{\circ} \mathrm{C}$. The highest fraction of retained austenite transformed into the strain-induced martensite in the specimen deformed at the lowest temperature, whereas the highest fraction of untransformed austenite was detected in the specimen deformed at the highest temperature.

A deformation temperature affects the SFE value [33]. Hence, the deformation behavior of retained austenite is strongly related to this factor. A low SFE value promotes large stacking faults and formation of hcp martensite and bcc martensite (for SFE lower than $25 \mathrm{~mJ} / \mathrm{m}^{2}$ ), medium SFE values favor twinning (SFE in a range of $25-60 \mathrm{~mJ} / \mathrm{m}^{2}$ ), and high SFE values lead to conventional deformation by dislocation slip (SFE higher than $60 \mathrm{~mJ} / \mathrm{m}^{2}$ ). In the literature, there are several works concerning the determination of SFE in single-phase high-Mn austenitic steels [35-37]. However, the SFE measurement of the austenitic phase in medium-Mn steels is more difficult due to their multiphase microstructure and numerous factors affecting the SFE. Chandan et al. [38] reported that SFE of retained austenite in a $0.18 \mathrm{C}-4.7 \mathrm{Mn}-0.8 \mathrm{Si}-0.4 \mathrm{Al}$ steel varies from 9 to $20 \mathrm{~mJ} /$ 

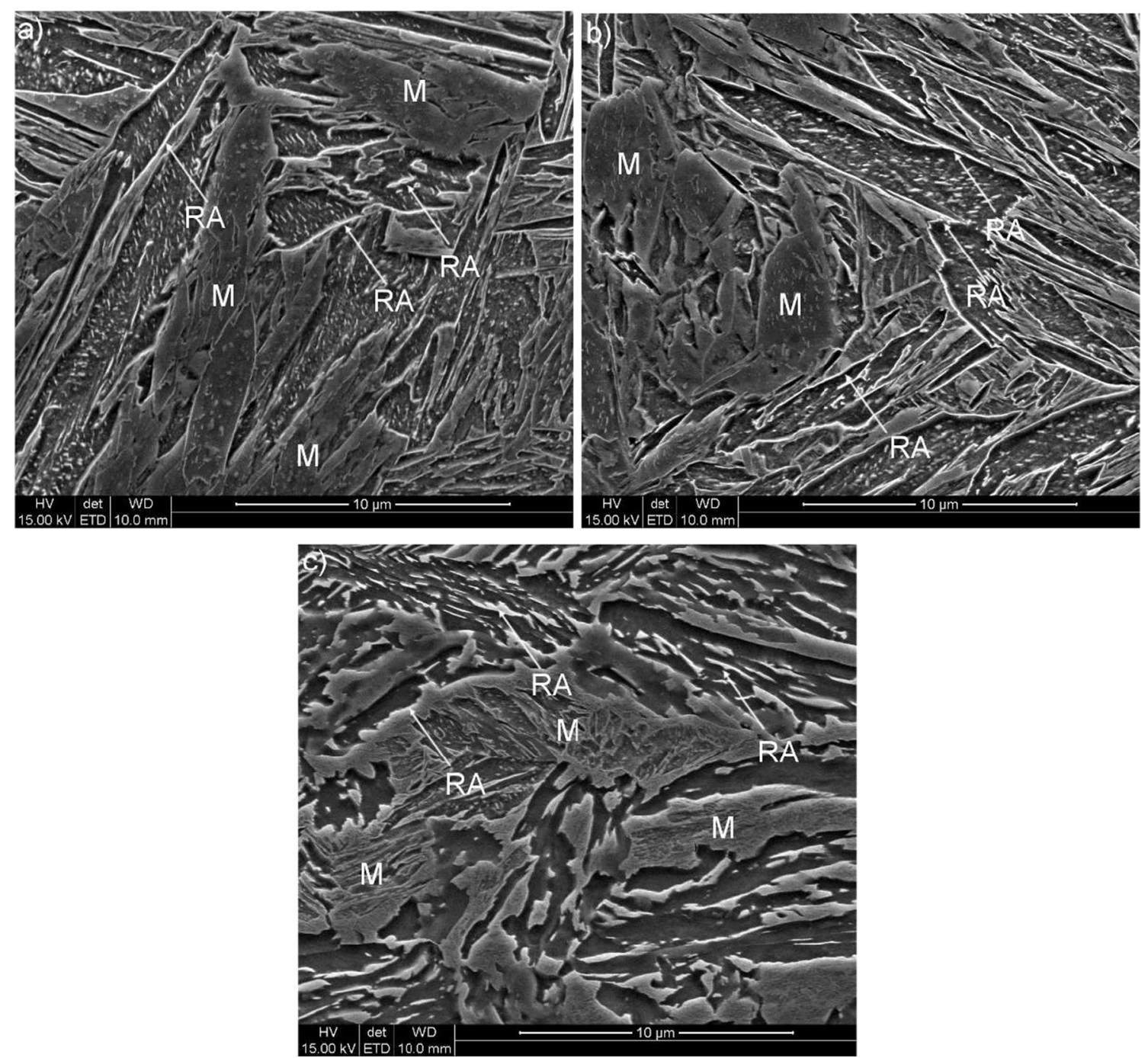

Fig. 4 Scanning electron microscope (SEM) micrographs of investigated steel deformed at $20{ }^{\circ} \mathrm{C}(\mathbf{a}), 100{ }^{\circ} \mathrm{C}(\mathbf{b})$ and $200{ }^{\circ} \mathrm{C}(\mathbf{c}) . M$ martensite, $R A$ retained austenite

$\mathrm{m}^{2}$ depending on the annealing time. In the current study, the SFE of RA determined by using JMatPro software [39] was ca. $5 \mathrm{~mJ} / \mathrm{m}^{2}$ at room temperature (similar to that reported by Chandan). Therefore, the strain-induced martensitic transformation controls the deformation mechanism of RA in the investigated $0.16 \mathrm{C}-4.7 \mathrm{Mn}-1.6 \mathrm{Al}-0.2 \mathrm{Si}$ steel up to $140^{\circ} \mathrm{C}$. With increasing temperature to $200^{\circ} \mathrm{C}$, the SFE rises to ca. $40 \mathrm{~mJ} / \mathrm{m}^{2}$ [39]. It means that at the highest deformation temperature $\left(200^{\circ} \mathrm{C}\right)$ twinning could also play some role [33]. However, its role is limited and difficult to confirm due to carbide precipitation and a related drop in retained austenite amount, which will be discussed later.

Luo et al. [40] investigated the effect of deformation temperature $\left(0-300{ }^{\circ} \mathrm{C}\right)$ on the stability of retained austenite in intercritically annealed $\mathrm{Fe}-0.12 \mathrm{C}-0.3 \mathrm{Si}-7 \mathrm{Mn}$ steel. They noted that a significant fraction of retained austenite transformed into martensite in the temperature range
$0-100{ }^{\circ} \mathrm{C}$. In case of the highest deformation temperatures $\left(200\right.$ and $300^{\circ} \mathrm{C}$ ), almost all fractions of the retained austenite remained stable. The retained austenite in the tested steel $(5 \% \mathrm{Mn})$ was less stable due to the lack of additional partitioning of Mn into the $\gamma$ phase [41]. The application of intercritical annealing allows for the stabilization of the austenite with this element $[42,43]$. It does not take place for the hot-rolled $5 \mathrm{Mn}$ steel sheets cooled directly from the finishing rolling temperature [44].

The relatively low stability of the retained austenite in the investigated steel also at the temperatures of $140{ }^{\circ} \mathrm{C}$ and $200{ }^{\circ} \mathrm{C}$ may be associated with the occurrence of thermally activated processes following the plastic deformation. The precipitation of carbides depletes austenite in carbon, which reduces its stability (Fig. 8). Some fraction of plate carbides in bainitic ferrite laths was also observed (Fig. 8a). They were also revealed using SEM (Figs. 2 

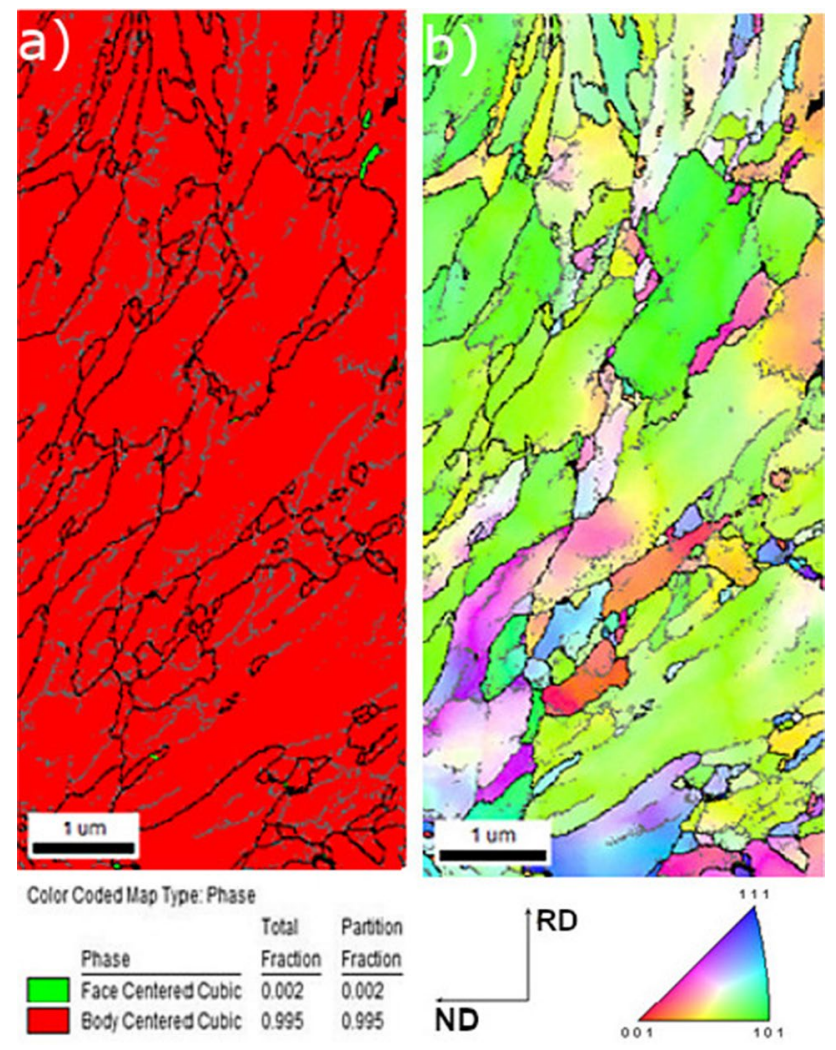

Fig. 5 Electron backscatter diffraction (EBSD) analysis of the steel deformed at $20{ }^{\circ} \mathrm{C}$. Phase distribution map-retained austenite (RA) as green (a), orientation map (b)

and 4). The presence of fine-dispersed carbide precipitates with a size $10-20 \mathrm{~nm}$ was identified in a bright-field mode at different magnifications (Fig. 8a-c) and confirmed by selected area diffraction (Fig. 8d). Images obtained using the scanning transmission electron microscopy (STEM) mode allowed for the identification of carbides based on their diffraction contrast (Fig. 8e) and chemical contrast (Fig. 8f). TEM observations have also shown that the specimen deformed at $200{ }^{\circ} \mathrm{C}$ revealed the presence of subgrains with various sizes resulting from the dynamic recovery (Fig. 9a, b). The presence of retained austenite with a size $150-200 \mathrm{~nm}$ can be observed at the highest deformation temperature (Fig. 9a). It confirms the result obtained by the XRD method (Fig. 7). Moreover, the reduced dislocation density can be observed both in the bainitic ferrite matrix and in the untransformed RA (Fig. 9a). The high-resolution TEM image (Fig. 9c) shows the presence of moire fringes. They indicate an initial stage of low-angle boundary formation (usually $<2^{\circ}$ ). Chen et al. [20] reported that for the medium-Mn steel containing 5\% Mn deformed at temperatures higher than $100{ }^{\circ} \mathrm{C}$, the significance of the TRIP effect decreased and different strain hardening mechanisms became dominant.
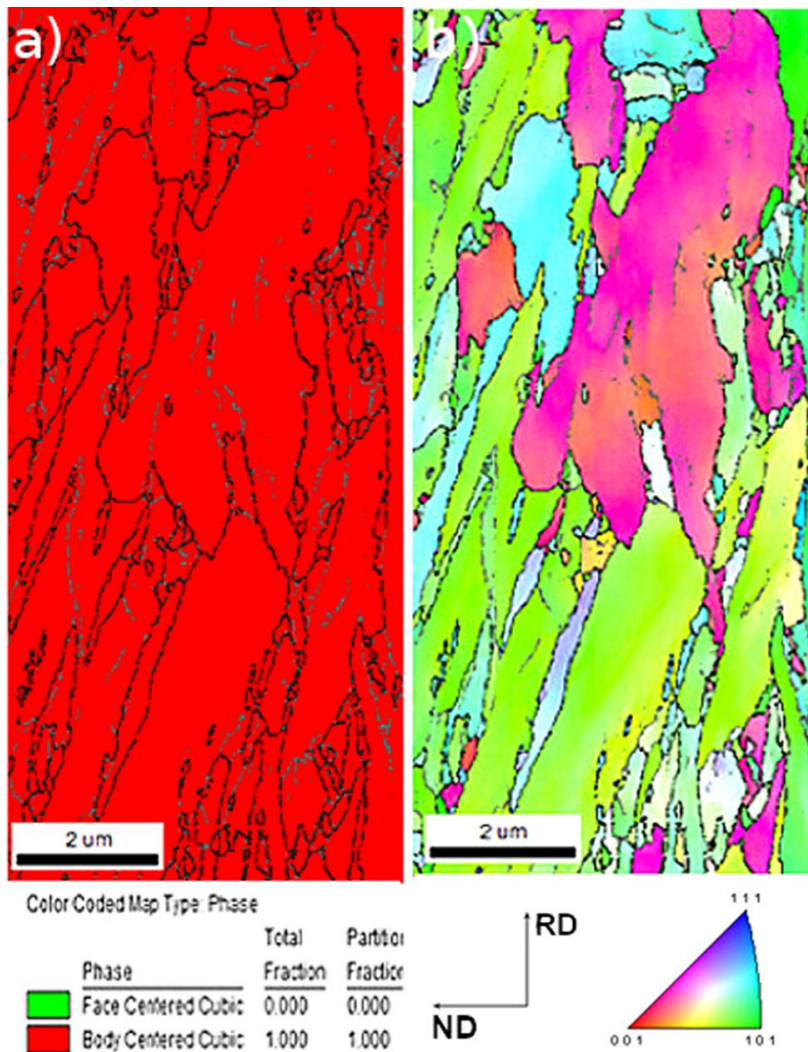

Fig. 6 Electron backscatter diffraction (EBSD) analysis of the steel deformed at $100{ }^{\circ} \mathrm{C}$. Phase distribution map-retained austenite (RA) as green (a), orientation map (b)

\subsection{Mechanical properties}

In order to understand the effect of deformation temperature on the mechanical properties, the investigated steel was tested over a wide temperature range from -60 to $200{ }^{\circ} \mathrm{C}$. The results are listed in Table 1. The true stress-true strain curves are presented in Fig. 10. One can see that the deformation temperature affects both strength and ductility of the investigated steel. The sample deformed at $-60{ }^{\circ} \mathrm{C}$ is characterized by the highest strength values (UTS $=1251 \mathrm{MPa}$, $\mathrm{YS}=995 \mathrm{MPa})$. However, the lowest total elongation value $(9.5 \%)$ was obtained at this deformation temperature (Table 1). It is related to the low stability of retained austenite, which intensively transforms into martensite at low strain values. The slope of the stress-strain curve for the sample deformed at $-20^{\circ} \mathrm{C}$ was smaller than for the sample deformed at $-60{ }^{\circ} \mathrm{C}$, which is related to the higher stability of retained austenite at this deformation temperature. The specimen deformed at $20^{\circ} \mathrm{C}$ shows relatively high mechanical properties. The tensile strength and yield stress values are $1215 \mathrm{MPa}$ and $925 \mathrm{MPa}$, respectively. The highest total elongation value (TEl) was obtained at this deformation temperature: $11.5 \%$. The YS/UTS ratio is 0.73 , which indicates 

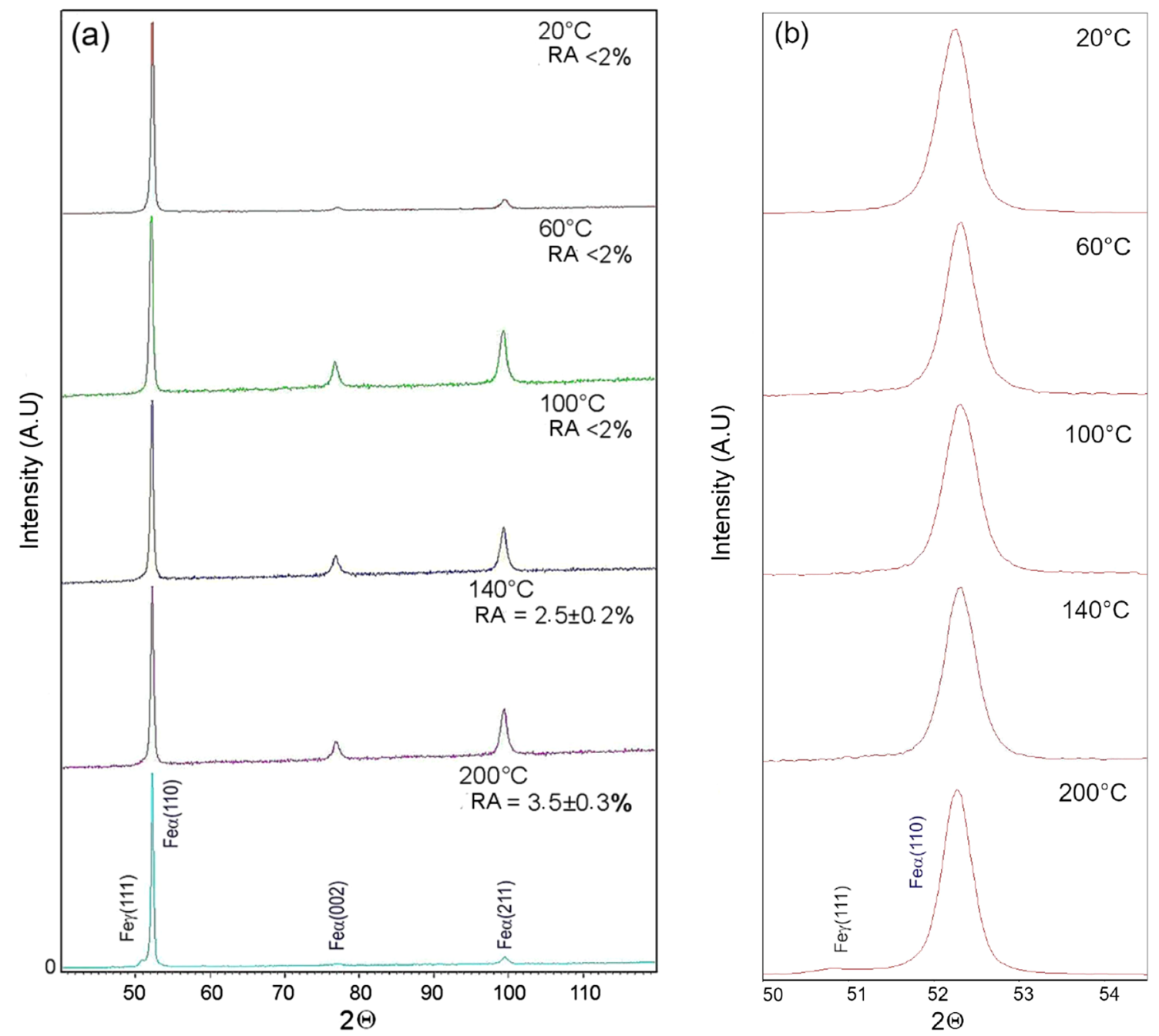

Fig. 7 The X-ray diffraction patterns of investigated steel deformed at temperatures $20-200{ }^{\circ} \mathrm{C}(\mathbf{a})$, XRD peaks of (111) $\gamma$ and (110) $\alpha(\mathbf{b})$

the relatively high work hardening potential. An increase in the deformation temperature to $60{ }^{\circ} \mathrm{C}$ results in a slight reduction in the mechanical properties. A further increase in deformation temperature to $100{ }^{\circ} \mathrm{C}$ is a reason of the detrimental in ductility and strength of the investigated steel.

An increase in the deformation temperature in a range of $20-100{ }^{\circ} \mathrm{C}$ resulted in a decrease in the total elongation value. Zou et al. [29] and Luo et al. [40] observed the same tendency in TRIP steels containing 2 and $7 \%$ of manganese, respectively. An increase in the deformation temperature above $100{ }^{\circ} \mathrm{C}$ results in the higher UTS and TEl values. However, most steels show an inverse tendency in strength behavior related to the thermal softening effect. It was reported by Tang et al. [45] and Madivala et al. [46]. Moreover, it is interesting that the value of TEl is similar to the specimen deformed at room temperature. Zou et al. [29] observed an increase in total elongation in $0.2 \mathrm{C}-2 \mathrm{Mn}-1.6 \mathrm{Si}$ steel deformed at $140{ }^{\circ} \mathrm{C}$ and $180{ }^{\circ} \mathrm{C}$. Moreover, they observed an increase in a yield strength value in a temperature range $100-180^{\circ} \mathrm{C}$. In the present study, the most pronounced increase in the YS value was noted for the specimen deformed at the highest temperature: $200{ }^{\circ} \mathrm{C}$. The increase in yield stress at this temperature is probably associated with strain aging [47]. This process usually is performed in a temperature range $140-200{ }^{\circ} \mathrm{C}$ within 20 min [48]. Similar conditions occurred during the tensile tests of samples in the present study. The samples were soaked for $30 \mathrm{~min}$ before the tensile tests at elevated temperatures, and then they were plastically deformed. The strain aging effect is related to the presence of mobile dislocations and formation of carbides. The mobile dislocations were formed during the earlier thermomechanical processing. The TEM micrographs in Fig. 8 confirm the formation of carbides at the highest deformation temperature, i.e., $200{ }^{\circ} \mathrm{C}$. The observed increase in total elongation is due to the dynamic recovery process observed at the highest deformation temperature (Fig. 9). 

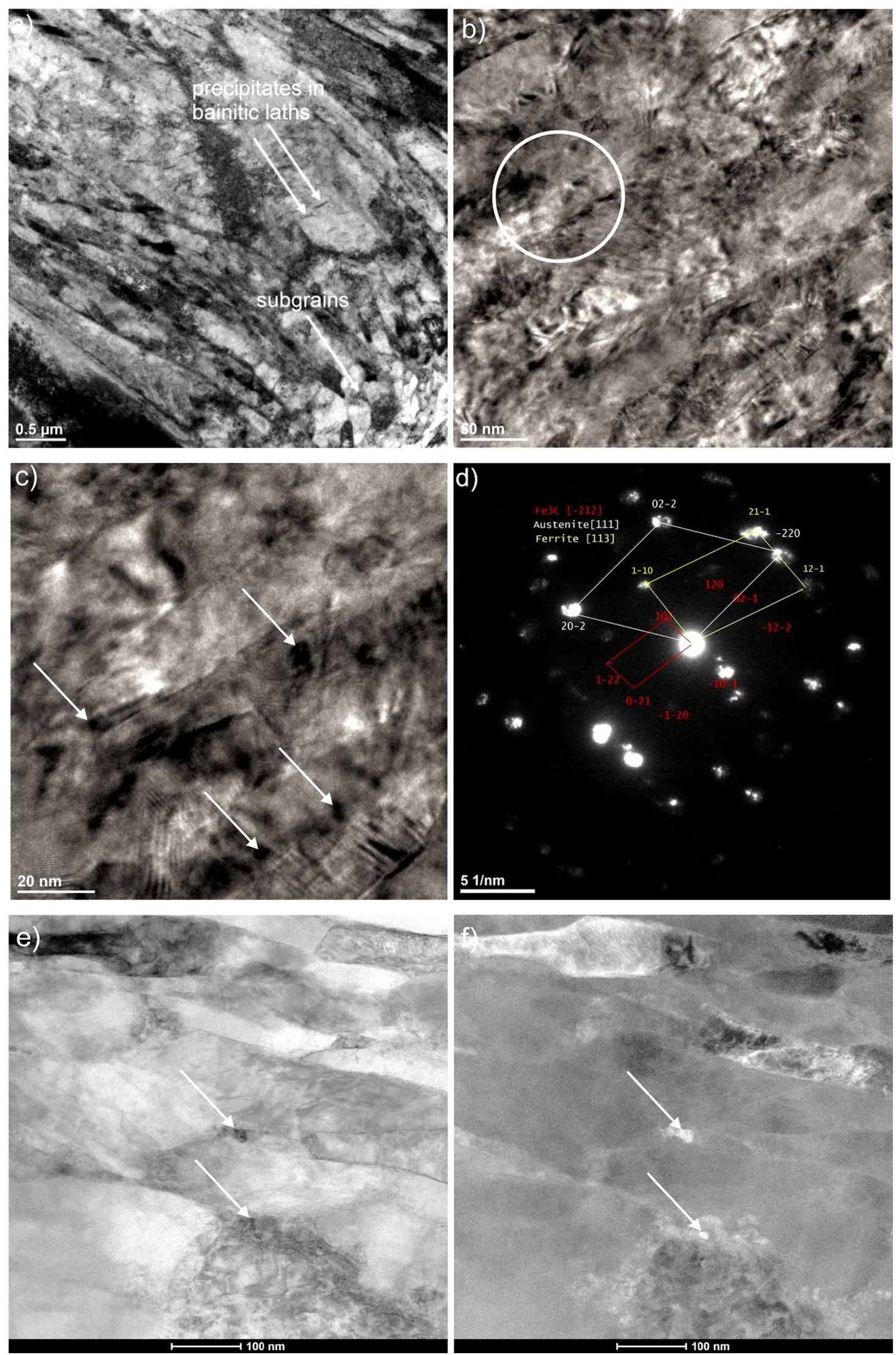
४Fig. 8 TEM microstructures of the specimen deformed at $200{ }^{\circ} \mathrm{C}$. Subgrains and precipitates - bright field (a), carbides marked by the white circle (b) carbides in a nanometer scale (c), selected area diffraction pattern from the area marked in the $\mathbf{b}$ image (d), bright-field STEM with diffraction contrast (e), HAADF STEM with chemical contrast (f)

A serrated flow behavior indicating the presence of Portevin-Le Chatelier (PLC) effect was observed in specimens deformed at $60{ }^{\circ} \mathrm{C}, 100{ }^{\circ} \mathrm{C}$ and $140{ }^{\circ} \mathrm{C}$. The appearance of characteristic serrations on the tensile curves was observed (Fig. 10). No PLC effect was noted in case of the specimens deformed at $-60{ }^{\circ} \mathrm{C},-20{ }^{\circ} \mathrm{C}, 20{ }^{\circ} \mathrm{C}$ and $200^{\circ} \mathrm{C}$. An increase in deformation temperature to $60{ }^{\circ} \mathrm{C}$ caused the appearance of the PLC effect in the early stage of plastic deformation. The observed oscillations were classified as type A according to [21]. The serrations were characterized by a small amplitude, and they occurred in a range of uniform elongation.

A similar type of the oscillation was observed in works [49] and [50] concerning medium-Mn steels. The range and amplitude of serrations were different depending on the deformation temperature. In the case of samples deformed at $100{ }^{\circ} \mathrm{C}$ and $140{ }^{\circ} \mathrm{C}$, the oscillations were observed at the final stage of deformation above the uniform deformation range. The type of oscillations observed in the sample deformed at $100{ }^{\circ} \mathrm{C}$ was classified as type B [21]. An increase in deformation temperature to $140{ }^{\circ} \mathrm{C}$ results in an increase in the oscillation amplitude and an increase in the extent of deformation in which they occurred. Above the 0.08 strain value, $B+C$ oscillations were observed [21]. In the case of the sample deformed at $200{ }^{\circ} \mathrm{C}$, no evidence of PLC phenomenon was observed. The disappearance of the plastic deformation instability at the highest deformation temperature was related to the accelerated carbon diffusivity (Fig. 8). In the literature [51], the mechanism of inhomogeneous plastic deformation associated with the Portevin-Le Chatelier phenomenon occurring in steels containing elevated manganese contents has been associated with the effect of dynamic strain aging (DSA).

The characterization of the PLC phenomenon in TRIPaided steels is a complicated issue due to their microstructure consisting of several phases and the TRIP effect occurring during deformation $[52,53]$. In the literature, there are several theories explaining the mechanism of PLC effect in medium-Mn steels. However, they are based mainly on theoretical models. The first theory explaining the PLC effect was proposed by Cottrell [54]. He reported that the plastic instability phenomenon is related to the interactions between solute atoms, such as carbon and mobile dislocations. This model was further developed for steels with increased content of manganese, such as medium-Mn steels and high-Mn steels. The PLC phenomenon in these steels is related to the interaction between dislocations and manganese-carbon clusters [55, 56]. The appearance of PLC effect is related to the carbon diffusion intensity which affects the reorientation time of $\mathrm{C}-\mathrm{Mn}$ pairs and the dislocation density. Min et al. [52] observed the similar temperature-dependent behavior. They reported that in $0.2 \mathrm{C}-2 \mathrm{Mn}-1.4 \mathrm{Si}$ steel serrations were not observed at deformation temperatures below $100{ }^{\circ} \mathrm{C}$ and above $250{ }^{\circ} \mathrm{C}$. They concluded that at low temperatures where serrations were not observed, dislocation pinning occurs very slow compared to dislocation unpinning. At high temperatures, where serrations do not occur, a solute diffusion rate is high enough to reduce the pinning force on dislocations. Kipelova et al. [53] reported that at the deformation temperatures higher than $350{ }^{\circ} \mathrm{C}$, PLC effect was not observed due to carbide precipitation, which reduces the concentration of carbon atoms in solid solution, terminating the serrations. Similar results were observed in the present study. Carbide precipitates observed in TEM images (Fig. 8) caused the reduction of $\mathrm{C}-\mathrm{Mn}$ pairs in solid solution. Therefore, the disappearance of serrations at $200{ }^{\circ} \mathrm{C}$ was noted.

The strain hardening rate $(\mathrm{d} \sigma / \mathrm{d} \varepsilon)$ as a function of true strain is plotted in Fig. 11. The shape of the curves is typical-as the deformation degree increases the $\mathrm{d} \sigma / \mathrm{d} \varepsilon$ values decrease. However, in steels with a high fraction of metastable retained austenite, a local increase in the $\mathrm{d} \sigma / \mathrm{d} \varepsilon$ value can be sometimes observed [20] due to the occurrence of intense TRIP effect. In the case of the investigated steel, no such effect was observed due to the relatively low amount of retained austenite in the initial state $11 \%$ (Fig. 3). The smallest strain hardening rate was noted for the sample deformed at $-60{ }^{\circ} \mathrm{C}(10,000 \mathrm{MPa})$, for which it decreased intensively as the degree of deformation increased. An increase in deformation temperature from -20 to $200{ }^{\circ} \mathrm{C}$ resulted in an increase in the slope of the $\mathrm{d} \sigma / \mathrm{d} \varepsilon$ curves. For the sample deformed at $60^{\circ} \mathrm{C}$, a different course of the $\mathrm{d} \sigma /$ $\mathrm{d} \varepsilon$ curve was observed. It is related to the PLC effect which occurred in the early stage of deformation. The hardening behavior was similar for the samples deformed at temperatures: $-20{ }^{\circ} \mathrm{C}, 20{ }^{\circ} \mathrm{C}, 60{ }^{\circ} \mathrm{C}, 100^{\circ} \mathrm{C}$ and $200{ }^{\circ} \mathrm{C}$. The highest work hardening rate was observed in case of the sample deformed at $140{ }^{\circ} \mathrm{C}$, i.e., $13,000 \mathrm{MPa}$, but this value decreased intensively as the deformation increased.

The values of work hardening exponent $(n)$ as a function of deformation temperature are shown in Fig. 12. The smallest value of the work hardening exponent was noted for the sample deformed at $-60{ }^{\circ} \mathrm{C}$. In this case, the $n$ value was $\sim 0.15$ at 0.03 strain. It is related to the low stability of the retained austenite at this temperature and a resulting high fraction of RA transformed into strain-induced martensite at low strain values [34]. The value of $n$ increased in the temperature range of -20 to $20^{\circ} \mathrm{C}$. The gradual increase in the $n$ value indicates the occurrence of the strain-induced martensitic transformation, which prevents the strain localization. 

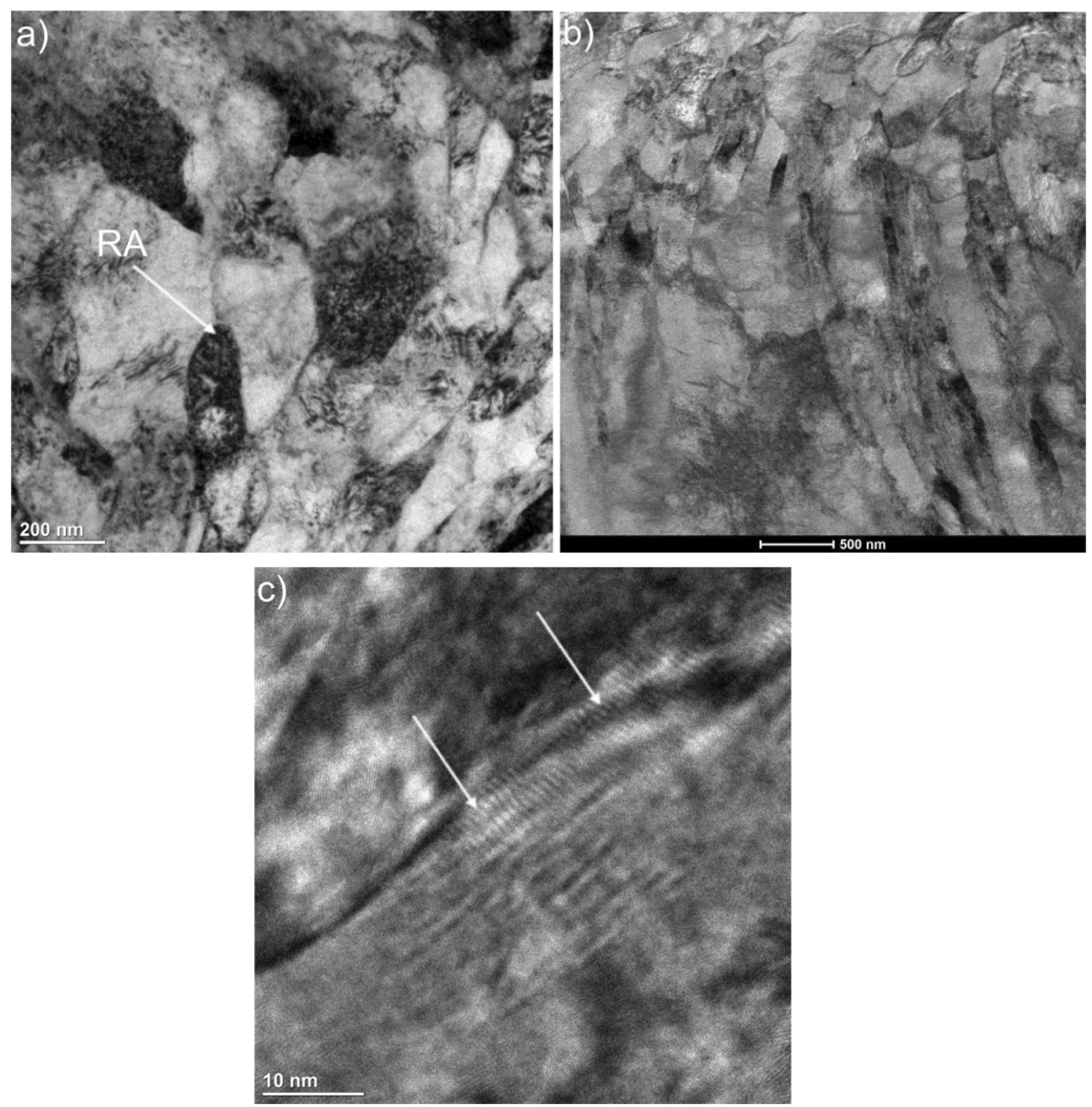

Fig. 9 TEM microstructures of the specimen deformed at $200{ }^{\circ} \mathrm{C}$. Subgrains—bright field (a), subgrains—HAADF STEM (b), moire fringes— high-resolution TEM (c)

Table 1 Mechanical properties of the investigated steel

\begin{tabular}{lllrl}
\hline $\begin{array}{l}\text { Deformation } \\
\text { temperature } \\
\left({ }^{\circ} \mathrm{C}\right)\end{array}$ & YS (MPa) & UTS (MPa) & TEl (\%) & YS/UTS \\
\hline-60 & $995 \pm 25$ & $1251 \pm 50$ & $9.5 \pm 1.4$ & 0.79 \\
-20 & $893 \pm 29$ & $1185 \pm 44$ & $10.3 \pm 1.6$ & 0.75 \\
20 & $925 \pm 30$ & $1215 \pm 41$ & $11.5 \pm 1.7$ & 0.73 \\
60 & $911 \pm 32$ & $1200 \pm 55$ & $10.4 \pm 1.2$ & 0.71 \\
100 & $904 \pm 23$ & $1180 \pm 43$ & $9.9 \pm 1.0$ & 0.74 \\
140 & $861 \pm 26$ & $1283 \pm 48$ & $11.4 \pm 1.5$ & 0.69 \\
200 & $980 \pm 31$ & $1246 \pm 52$ & $11.3 \pm 1.4$ & 0.76 \\
\hline
\end{tabular}

In the case of steel deformed at $60^{\circ} \mathrm{C}$, irregular oscillations were observed in the strain range $0.01-0.07$. The increase in the $\mathrm{n}$ value at $140{ }^{\circ} \mathrm{C}$ is due to the increased austenite stability (Fig. 7). The work hardening exponent value obtained at the deformation temperature of $200{ }^{\circ} \mathrm{C}$ is similar to these ones obtained at the temperatures $-20^{\circ} \mathrm{C}$ and $20^{\circ} \mathrm{C}$. It is attributed to the presence of dynamic thermally activated processes accompanying the deformation of steel (Figs. 8 and 9). The obtained results show the complex influence of the TRIP and PLC effects on the mechanical properties of the investigated steel, which are additionally triggered by the initiation of dynamic recovery process and the precipitation of carbides at the highest deformation temperatures (Fig. 13). 


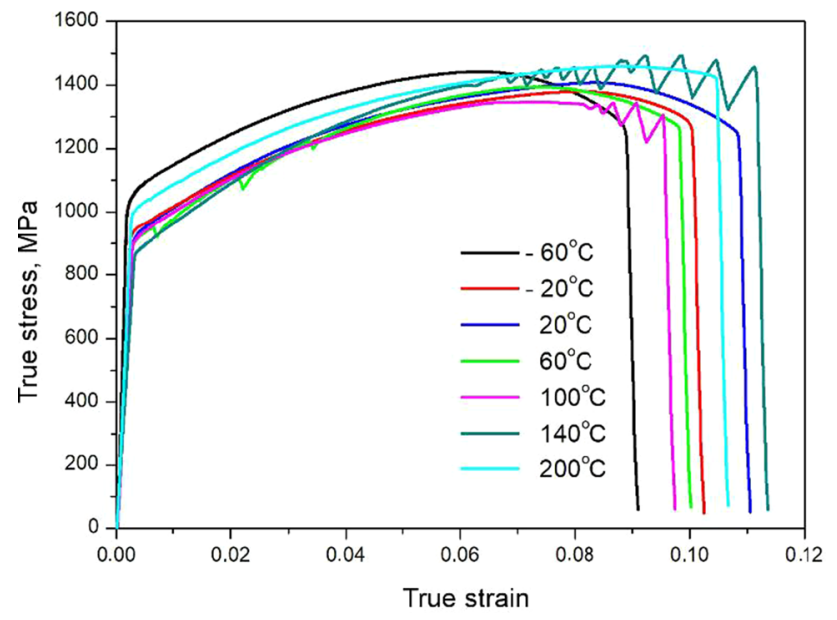

Fig. 10 True stress-true strain curves obtained at different deformation temperatures

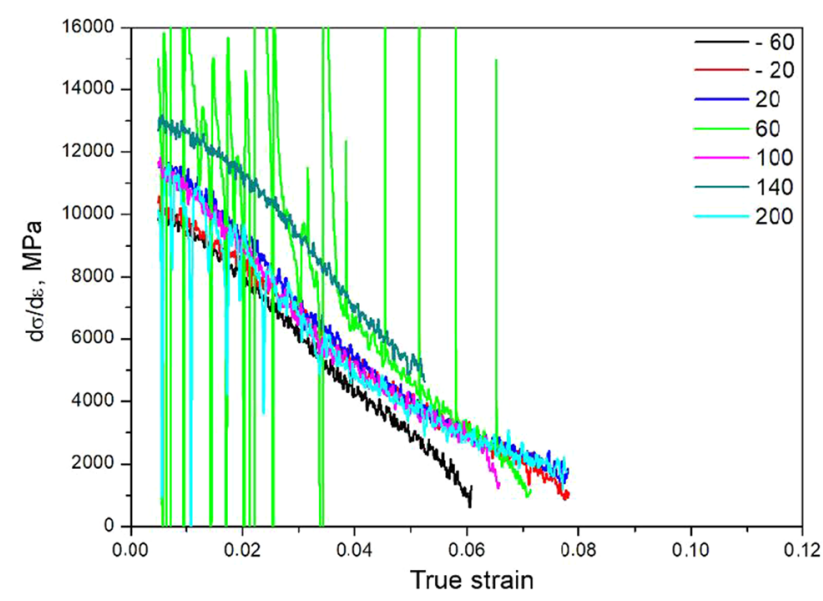

Fig. 11 Work hardening rate as a function of true strain for the steel deformed at different temperatures

Sugimoto's model was applied to determine the tendency of retained austenite to strain-induced martensite transformation:

$\ln \left(V_{\gamma 0}\right)-\ln \left(V_{\gamma}\right)=k_{\mathrm{s}} \varepsilon$,

where $V_{\gamma 0}$ is the initial volume fraction of retained austenite, $V_{\gamma}$ is the volume fraction of retained austenite at $\varepsilon$ true strain (at corresponding engineering strain levels of 0.025 , 0.05 and 0.075 ), and $k_{\mathrm{s}}$ is the stability constant.

The obtained results are affected by the initial amount of the retained austenite and its amount after deformation (at interrupted strain levels or at rupture conditions) at a given temperature. The fitting of the experimental data obtained for the kinetics of strain-induced martensitic transformation to the Sugimoto model is shown in Fig. 14. It is clearly seen

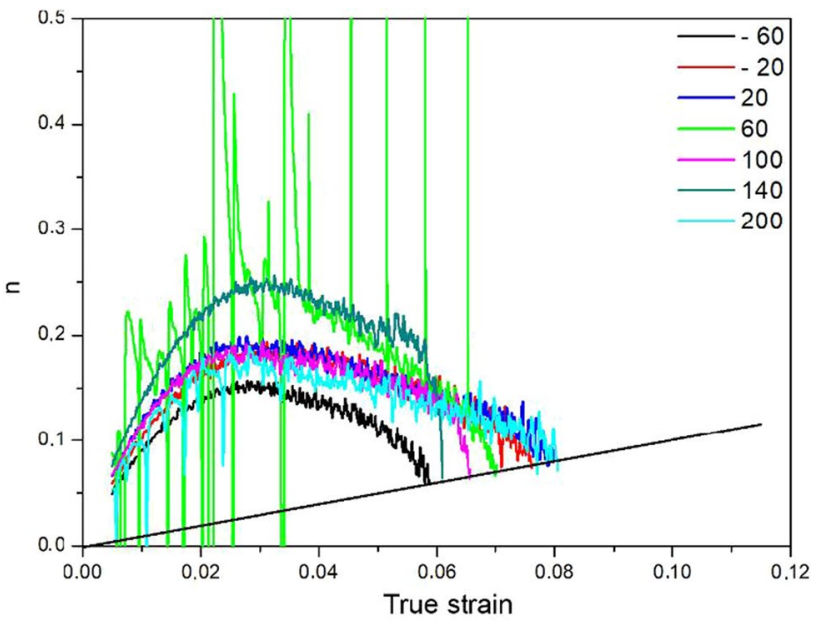

Fig. 12 Work hardening exponent $(n)$ changes as a function of true strain at different deformation temperatures

that the deformation temperature affects the austenite stability significantly. A lower $k_{\mathrm{s}}$ value means the higher mechanical stability of the RA. Under rupture conditions, retained austenite remained stable only in case of samples deformed at $140{ }^{\circ} \mathrm{C}$ and $200^{\circ} \mathrm{C}$.

The obtained results showed that as the temperature increases the stability of RA rises. It means that the retained austenite is more stable and the strain-induced martensite transformation is suppressed at higher temperatures. At subzero temperatures, $k_{\mathrm{s}} \sim 10-12$, which means a relatively low stability of retained austenite and the related rapid strain-induced martensitic transformation. At room temperature, $k_{\mathrm{s}}=7.8$, which is close to the value reported by Krizan et al. [57] for the $0.22 \mathrm{C}-1.5 \mathrm{Mn}-0.44 \mathrm{Si}-1.34 \mathrm{Al}$ TRIP steel $\left(k_{\mathrm{s}}=9\right)$. However, their steel was more resistant against the strain-induced martensitic transformation, which was reflected in the stability constant decrease to $k_{\mathrm{s}}=1$ at $100{ }^{\circ} \mathrm{C}$. In our steel, the $k_{\mathrm{s}}$ value at $100{ }^{\circ} \mathrm{C}$ is 6.9 (Fig. 14) showing only the moderate stability of retained austenite in a whole temperature range applied. The mechanical stability is also lower compared to the $0.2 \mathrm{C}-5 \mathrm{Mn}$ steel deformed in a temperature range -80 to $100{ }^{\circ} \mathrm{C}$ by Chen et al. [20], who reported the $k_{\mathrm{s}}$ value $\sim 1.7$ at $100{ }^{\circ} \mathrm{C}$. Even with a further temperature increase to $200^{\circ} \mathrm{C}$, the stability of the $\gamma$ phase in our steel rises only a little bit achieving the $k_{\mathrm{s}}=5.5$.

Figure 15 shows the temperature dependence of the $k_{\mathrm{s}}$ value of the Sugimoto model. The curve is well fitted by the second-degree polynomial. The minimum $k_{\mathrm{s}}$ value at $200{ }^{\circ} \mathrm{C}$ means a change of the conditions for the strain-induced martensitic transformations. This trend was observed by Sugimoto et al. [58], who reported that the mechanical stability of retained austenite in $0.4 \mathrm{C}-1.5 \mathrm{Si}-1.5 \mathrm{Mn}$ steel below $200{ }^{\circ} \mathrm{C}$ was mainly controlled by the strain-induced martensitic transformation. However, above $200-250{ }^{\circ} \mathrm{C}$ they 
Fig. 13 Effect of temperature on yield stress, tensile strength and total elongation; factors affecting mechanical properties of the investigated steel are plotted
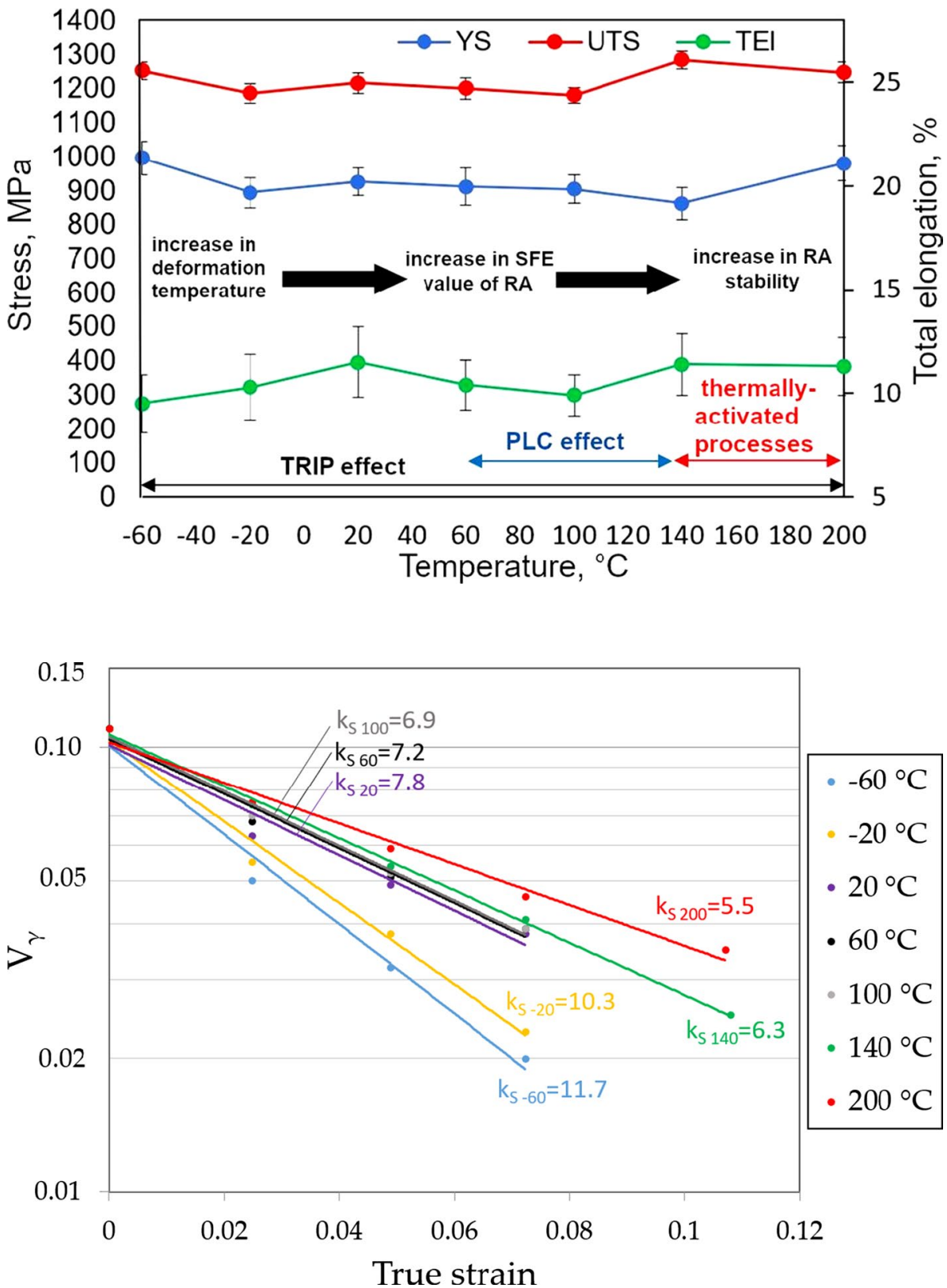

Fig. 14 Fitting of the experimental data to the Sugimoto model at the different deformation temperatures in the mechanical stability of retained austenite should be expected above $200{ }^{\circ} \mathrm{C}$ like in the described above steels, but it requires further investigations.

\section{Conclusions}

The work concerns a detailed study of the mechanical stability of retained austenite in TRIP-assisted 0.16C-4.7Mn-1.6Al-0.2Si medium-Mn steel deformed in static tensile tests performed in the temperature range $-60{ }^{\circ} \mathrm{C}$ to $200^{\circ} \mathrm{C}$. The complex qualitative and quantitative assessment techniques were applied to identify the temperature-dependent behavior of strain-induced 


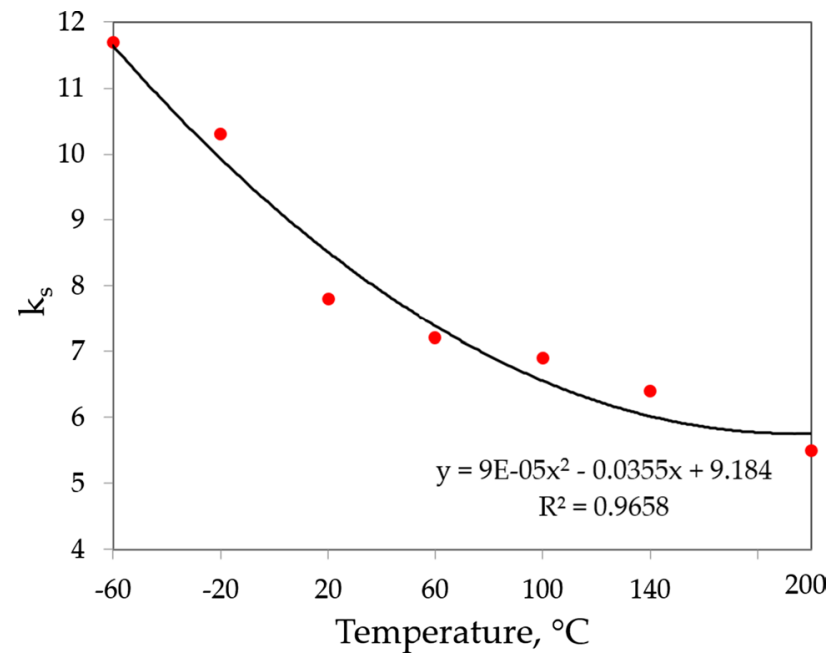

Fig. 15 The temperature dependence of the $k_{\mathrm{s}}$ value of the Sugimoto model

martensitic transformation of metastable retained austenite. The main findings of the present study were as follows:

- Temperature of the plastic deformation affected the stability of retained austenite significantly. An increase in the deformation temperature resulted in the reduced development of the TRIP effect due to the higher mechanical stability of retained austenite and a corresponding rise in its SFE value. Some fraction of retained austenite remained stable only at the highest deformation temperatures $140{ }^{\circ} \mathrm{C}$ and $200{ }^{\circ} \mathrm{C}$, whereas at the lower temperatures almost all fractions of RA transformed into strain-induced martensite.

- Mechanical properties of the investigated medium-Mn steel depended on the deformation temperature. The most beneficial mechanical properties were obtained for the specimens deformed at $20{ }^{\circ} \mathrm{C}$ and $200{ }^{\circ} \mathrm{C}$. In case of the specimen deformed at room temperature, the UTS and TEl values were $1215 \mathrm{MPa}$ and $11.5 \%$, whereas YS/UTS ratio was 0.73. It was due to the gradual strain-induced martensitic transformation. At the highest deformation temperature $200{ }^{\circ} \mathrm{C}$, the mechanical properties were affected by the thermally activated processes-dynamic recovery and carbide precipitation.

- Portevin-Le Chatelier phenomenon was observed in the specimens deformed at $60{ }^{\circ} \mathrm{C}, 100{ }^{\circ} \mathrm{C}$ and $140{ }^{\circ} \mathrm{C}$. A value of critical strain required for the initiation of the PLC effect, an amplitude and a range of plastic flow serrations depended on the deformation temperature. The disappearance of plastic deformation instability at the highest deformation temperature of $200{ }^{\circ} \mathrm{C}$ was due to the accelerated carbon diffusivity.
- The Sugimoto model indicated the moderate mechanical stability of retained austenite expressed by the $k_{\mathrm{s}}$ values from 12 at $-60{ }^{\circ} \mathrm{C}$ to 5.5 at $200{ }^{\circ} \mathrm{C}$. The stability of the $\gamma$ phase is affected by precipitation phenomena in a temperature range of $140-200{ }^{\circ} \mathrm{C}$.

Acknowledgements A. Kozłowska and A. Grajcar acknowledge the internship stays at Faculty for Engineering and Environmental Sciences, University of Applied Sciences Upper Austria in Wels (2019).

Funding The financial support of the National Science Center, Poland, is gratefully acknowledged, Grant No. 2017/27/B/ST8/02864.

\section{Compliance with ethical standards}

Conflict of interest The authors declare no conflict of interest.

Ethical statement The authors state that the research was conducted according to ethical standards.

Open Access This article is licensed under a Creative Commons Attribution 4.0 International License, which permits use, sharing, adaptation, distribution and reproduction in any medium or format, as long as you give appropriate credit to the original author(s) and the source, provide a link to the Creative Commons licence, and indicate if changes were made. The images or other third party material in this article are included in the article's Creative Commons licence, unless indicated otherwise in a credit line to the material. If material is not included in the article's Creative Commons licence and your intended use is not permitted by statutory regulation or exceeds the permitted use, you will need to obtain permission directly from the copyright holder. To view a copy of this licence, visit http://creativecommons.org/licenses/by/4.0/.

\section{References}

1. Suh WD, Kim SJ. Medium Mn transformation-induced plasticity steels: recent progress and challenges. Scr Mater. 2017;126:63-7.

2. Kokosza A, Pacyna J. Influence of austenitising temperature on kinetics of phase transformations in medium carbon TRIP steel. Mater Sci Technol. 2015;31:802-7.

3. Gramlich A, Emmrich R, Bleck W. Austenite reversion tempering-annealing of $4 \mathrm{wt} \%$ manganese steels for automotive forging application. Metals. 2019. https://doi.org/10.3390/met9050575.

4. Gronostajski Z, Pater Z, Madej L, Gontarz A, Lisiecki L, Lukaszek-Solek A, Luksza J, Mróz S, Muskalski Z, Muzykiewicz W, Pietrzyk M, Sliwa RE, Tomczak J, Wiewiórowska S, Winiarski G, Zasadzinski J, Ziólkiewicz S. Recent development trends in metal forming. Arch Civil Mech Eng. 2019;19:898-941.

5. Li ZC, Ding H, Misra RDK, Cai ZH. Microstructure-mechanical property relationship and austenite stability in medium-Mn TRIP steels: the effect of austenite-reverted transformation and quenching-tempering treatments. Mater Sci Eng A. 2017;682:211-9.

6. Valdes-Tabernero MA, Celada-Casero C, Sabirov I, Kumar A, Petrov RH. The effect of heating rate and soaking time on microstructure of an advanced high strength steel. Mater Charact. 2019;155:109822.

7. Glover A, Gibbs PJ, Liu C, Brown DW, Clausen B, Speer JG, De Moor E. Deformation behavior of a double soaked medium 
manganese steel with varied martensite strength. Metals. 2019. https://doi.org/10.3390/met9070761.

8. Korpała G, Hisker F, Hammer B, Heller T, Kawalla R, Prahl U. The influence of hot-rolling conditions on the content and morphology of retained austenite in ultra-high strength bainitic steel and its mechanical properties. Steel Res Int. 2019;90:1800386.

9. Gronostajski Z, Niechajowicz A, Kuziak R, Krawczyk J, Polak S. The effect of the strain rate on the stress-strain curve and microstructure of AHSS. J Mater Process Technol. 2017;242:246-59.

10. Samek L, De Moor E, Penning J, Speer JG, De Cooman BC. Static strain aging of microstructural constituents in transformationinduced-plasticity steel. Metall Mater Trans A. 2008;39:2542-54.

11. Xia P, Sabirov I, Molina-Aldareguia J, Verleysen P, Petrov R. Mechanical behavior and microstructure evolution of a quenched and partitioned steel during drop weight impact and punch testing. Mater Sci Eng A. 2018;737:18-26.

12. Sevsek S, Haase C, Bleck W. Strain-rate-dependent deformation behavior and mechanical properties of a multi-phase mediummanganese steel. Metals. 2019. https://doi.org/10.3390/met90 30344.

13. Kozłowska A, Janik A, Radwański K, Grajcar A. Microstructure evolution and mechanical stability of retained austenite in medium-Mn steel deformed at different temperatures. Materials. 2019. https://doi.org/10.3390/ma12183042.

14. Rusinek A, Klepaczko JR. Experiments on heat generated during plastic deformation and stored energy for TRIP steels. Mater Des. 2009;30:35-48.

15. Kim H, Lee J, Barlat F, Kim D, Lee MG. Experiment and modeling to investigate the effect of stress state, strain and temperature on martensitic phase transformation in TRIP-assisted steel. Acta Mater. 2015;97:435-44.

16. Rong T, Lin L, De Cooman BC, Chen WX, Peng S. Effect of temperature and strain rate on dynamic properties of low silicon TRIP steel. J Iron Steel Res Int. 2006;13:51-6.

17. Asghari A, Zarei-Hanzaki A, Eskandari M. Temperature dependence of plastic in a modified transformation-twinning induced plasticity steel. Mater Sci Eng A. 2013;579:150-6.

18. Li X, Wei L, Chen L, Zhao Y, Misra RDK. Work hardening behavior and tensile properties of a high-Mn damping steel at elevated temperatures. Mater Charact. 2018;144:575-83.

19. Rana R, De Moor E, Speer JG, Matlock DK. On the importance of adiabatic heating on deformation behavior of medium-manganese sheet steels. JOM. 2018;70:706-13.

20. Chen S, Cao Z, Wang C, Huang C, Ponge D, Cao W. Effect of volume fraction and mechanical stability of austenite on ductility of medium Mn steel. J Iron Steel Res Int. 2019;26:1209-18.

21. Kozłowska A, Grzegorczyk B, Staszuk M, Nuckowski PM, Grajcar A. Analysis of plastic deformation instabilities at elevated temperatures in hot-rolled medium-Mn steel. Materials. 2019. https://doi.org/10.3390/ma12244184.

22. Jabłońska MB, Kowalczyk K. Microstructural aspects of energy absorption of high manganese steels. Procedia Manuf. 2019;27:91-7.

23. Grajcar A, Skrzypczyk P, Kozłowska A. Effects of temperature and time of isothermal holding on retained austenite stability in medium-Mn steels. Appl Sci. 2018. https://doi.org/10.3390/app81 12156.

24. ASTM E8/E8M-13a. Standard test methods for tension testing of metallic materials. West Conshohocken: ASTM International; 2013.

25. Samek L, De Moor E, Penning J, De Cooman BC. Influence of alloying elements on the kinetics of strain-induced martensitic nucleation in low-alloy multiphase high-strength steels. Metall Mater Trans A. 2006;37:109-23.
26. ASTM E975-3. Standard practice for X-ray determination of retained austenite in steel with near random crystallographic orientation. West Conshohocken: ASTM International; 2013.

27. Tang ZY, Huang JN, Ding H, Cai ZH, Misra RDK. Austenite stability and mechanical properties of a low-alloyed ECAPed TRIPaided steel. Mater Sci Eng A. 2018;724:95-102.

28. Gnaupel-Herolda T, Creuziger A. Diffraction study of the retained austenite content in TRIP steels. Mater Sci Eng A. 2011;528:3594-600.

29. Zou DX, Li SH, He J. Temperature and strain rate dependent deformation induced martensitic transformation and flow behavior of quenching and partitioning steels. Mater Sci Eng A. 2017;80:54-63.

30. Pereloma EV, Gazder AA, Timokhina IB. Addressing retained austenite stability in advanced high strength steels. Mater Sci Forum. 2012;738:212-6.

31. Sugimoto K, Tanino H, Kobayashi J. Impact toughness of medium-Mn transformation-induced plasticity-aided steels. Steel Res Int. 2015;86:1151-60.

32. Sun B, Fazeli F, Scott C, Guo B, Aranas C, Chu X Jr, Jahazi M, Yue S. Microstructural characteristics and tensile behavior of medium manganese steels with different manganese additions. Mater Sci Eng A. 2018;729:496-507.

33. Zambrano OA. Stacking fault energy maps of $\mathrm{Fe}-\mathrm{Mn}-\mathrm{Al}-\mathrm{C}-$ Si steels: effect of temperature, grain size, and variations in compositions. J Eng Mater Technol. 2016. https://doi. org/10.1115/1.4033632.

34. Zhang M, Li L, Ding J, Wu Q, Wang YD, Almer J, Guo F, Ren Y. Temperature-dependent micromechanical behavior of medium-Mn transformation-induced-plasticity steel studied by in situ synchrotron X-ray diffraction. Acta Mater. 2017;141:294-303.

35. Pierce DT, Jiménez JA, Bentley J, Raabe D, Oskay C, Wittig JE. The influence of manganese content on the stacking-fault and austenite/e-martensite interfacial energies in $\mathrm{Fe}-\mathrm{Mn}-(\mathrm{Al}-$ Si) steels investigated by experiment and theory. Acta Mater. 2014;68:238-53.

36. Allain S, Chateau JP, Bouaziz O, Migot S, Guelton N. Correlations between the calculated stacking fault energy and the plasticity mechanisms in $\mathrm{Fe}-\mathrm{Mn}-\mathrm{C}$ alloys. Mater Sci Eng A. 2004;387-389:158-62

37. Wittig JE, Pozuelo M, Jiménez JA, Frommeyer G. Temperature dependent deformation mechanisms of a high-nitrogen manganese austenitic stainless steel. Steel Res Int. 2009;80:66-70.

38. Chandan AK, Mishra G, Mahato B, Chowdhury SG, Kundu S, Chakraborty J. Stacking fault energy of austenite phase in medium manganese steel. Metall Mater Trans A. 2019;50:4851-66.

39. Sente software Ltd. A collection of free downloadable papers on the development and application of JMatPro. 2005. http://www. sentesoftware.co.uk/biblio.html. Accessed 10 Sept 2020.

40. Luo L, Li W, Wang L, Zhou S, Jin X. Tensile behaviors and deformation mechanism of a medium Mn-TRIP steel at different temperatures. Mater Sci Eng A. 2017;682:698-703.

41. $\mathrm{Hu} \mathrm{B}, \mathrm{Luo} \mathrm{H}$. A novel two-step intercritical annealing process to improve mechanical properties of medium Mn steel. Acta Mater. 2019;176:250-63.

42. Hu B, Cheng GJ, Wei H, Ming Y, Huang X, Luo HW. Super-highstrength and formable medium Mn steel manufactured by warm rolling process. Acta Mater. 2019;174:131-41.

43. Speer J, Rana R, Matlock D, Glover A, Thomas G, De Moor E. Processing variants in medium-Mn steels. Metals. 2019. https:// doi.org/10.3390/met9070771.

44. Tan X, Ponge D, Lu W, Xu Y, He H, Yan J, Wu D, Raabe D. Joint investigation of strain partitioning and chemical partitioning in ferrite-containing TRIP-assisted steels. Acta Mater. 2020;186:374-88. 
45. Tang Z, Huang J, Ding H, Cai Z, Zhang D, Misra D. Effect of deformation temperature on mechanical properties and deformation mechanisms of cold-rolled low $\mathrm{C}$ high Mn TRIP/TWIP steel. Metals. 2018. https://doi.org/10.3390/met8070476.

46. Madivala M, Schwedt A, Wong SL, Roters F, Prahl U, Bleck W. Temperature dependent strain hardening and fracture behavior of TWIP steel. Int J Plast. 2018;104:80-103.

47. Ramazani A, Bruehl S, Gerber T, Bleck W, Prahl U. Quantification of bake hardening effect in DP600 and TRIP700 steels. Mater Des. 2014;57:479-86.

48. Samek L, Dykas J, De Moor E, Grajcar A. Strain-ageing of lowalloyed multiphase high-strength steels. Metals. 2020. https://doi. org/10.3390/met10040439.

49. Callahan M, Huber O, Hild F, Perlade A, Schmitt JH. Coincidence of strain-induced TRIP and propagative PLC bands in medium Mn steels. Mater Sci Eng A. 2017;703:391-400.

50. Sun B, Vanderesse N, Fazeli F, Scott C, Chen J, Bocher P, Jahazi $\mathrm{M}$, Yue S. Discontinuous strain-induced martensite transformation related to the Portevin-Le Chatelier effect in a medium manganese steel. Scr Mater. 2017;133:9-13.

51. Field DM, Van Aken DC. Dynamic strain ageing phenomena and tensile response of medium-Mn TRIP steel. Metall Mater Trans A. 2018;49:1152-66.

52. Min J, Hector LG, Zhang LJ, Sund L, Carsley JE, Lin J. Plastic instability at elevated temperatures in a TRIP-assisted steel. Mater Des. 2016;95:370-86.
53. Kipelova A, Kaibyshev R, Skorobogatykh V, Schenkova I. Portevin-Le Chatelier effect in an E911 creep resistant steel with 3\% Co additives. J Phys Conf Ser. 2010;240:012100.

54. Cottrell AH. A note on the Portevin-Le Chatelier effect. Lond Edinb Dublin Philos Mag J Sci. 1953;44:829-32.

55. Owen WS, Grujicic M. Strain ageing of austenitic Hadfield manganese steel. Acta Metall. 1999;47:111-26.

56. Hickel T, Sandlöbes S, Marceau RKW, Dick A, Bleskov I, Neugebauer J, Raabe D. Impact of nanodiffusion on the stacking fault energy in high-strength steels. Acta Mater. 2014;75:147-55.

57. Krizan D, De Cooman BC. Analysis of the strain-induced martensitic transformation of retained austenite in cold rolled microalloyed TRIP steel. Steel Res Int. 2008;79:513-22.

58. Sugimoto K, Kobayashi M, Hashimoto S. Ductility and straininduced transformation in a high-strength transformationinduced plasticity-aided dual-phase steel. Metall Mater Trans A. 1992;23:3085-91.

59. Sugimoto K, Usui N, Kobayashi M, Hashimoto S. Effects of volume fraction and stability of retained austenite on ductility of TRIP-aided dual-phase steels. ISIJ Int. 1992;32:1311-8.

Publisher's Note Springer Nature remains neutral with regard to jurisdictional claims in published maps and institutional affiliations. 